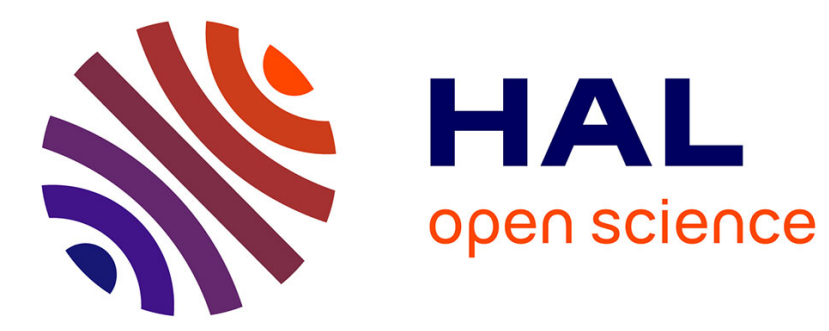

\title{
Bridging kinematic measurements and crystal plasticity models in austenitic stainless steels
}

\author{
A Guery, F Latourte, F Hild, Stéphane Roux
}

\section{To cite this version:}

A Guery, F Latourte, F Hild, Stéphane Roux. Bridging kinematic measurements and crystal plasticity models in austenitic stainless steels. SEM 2015 Annual Conference and Exposition on Experimental and Applied Mechanics, Jun 2015, Costa Mesa, United States. hal-01171687

\section{HAL Id: hal-01171687 \\ https://hal.science/hal-01171687}

Submitted on 6 Jul 2015

HAL is a multi-disciplinary open access archive for the deposit and dissemination of scientific research documents, whether they are published or not. The documents may come from teaching and research institutions in France or abroad, or from public or private research centers.
L'archive ouverte pluridisciplinaire HAL, est destinée au dépôt et à la diffusion de documents scientifiques de niveau recherche, publiés ou non, émanant des établissements d'enseignement et de recherche français ou étrangers, des laboratoires publics ou privés. 


\title{
BRIDGING KINEMATIC MEASUREMENTS AND CRYSTAL PLASTICITY MODELS IN AUSTENITIC STAINLESS STEELS
}

\author{
A. Guery ${ }^{1,2}$, F. Latourte ${ }^{1}$, F.Hild ${ }^{2}$ and S. Roux ${ }^{2}$ \\ ${ }^{1}$ EDF R\&D, Site des Renardières, Avenue des Renardières - Ecuelles, 77818 Moret-sur-Loing, France \\ ${ }^{2}$ LMT-Cachan, ENS Cachan / CNRS / University Paris Saclay \\ 61 Avenue du Président Wilson, 94235 Cachan Cedex, France \\ Email: adrien.guery@edf.fr
}

\begin{abstract}
A digital image correlation procedure is developed to perform kinematic measurements on the surface of $316 \mathrm{LN}$ austenitic steel polycrystals. A sequence of images is acquired using a Scanning Electron Microscope (SEM) during in situ tensile tests for various mean grain sizes. To enable digital image correlation, a speckle pattern adapted to the microscopic scale is deposited onto the specimen surface by microlithography. The knowledge of the microstructure at the surface allows for kinematic measurements to be performed using an unstructured finite element mesh consistent with the grain boundaries. The same mesh is then used for the simulation of each tensile test on the experimental microstructure with the measured nodal displacements prescribed as boundary conditions. A crystal plasticity law is considered to simulate the observed strain heterogeneities. An inverse identification method is proposed for the determination of the sought constitutive parameters based on both the local displacement fields and the material homogenized behavior. The parameters associated with isotropic hardening at the grain level are thus identified.
\end{abstract}

Keywords: Austenitic Steel, Crystal Plasticity, Digital Image Correlation, Identification, SEM

\section{INTRODUCTION}

The mechanical behavior of austenitic stainless steel needs to be well known since this material is used in Pressurized Water Reactor (PWR) internals. In particular, to ensure the in-service strength of components, predictive constitutive models are established in micromechanical frameworks and are designed to account for material ageing due to irradiation [1]. Experimentally, the characteristic dimensions of the polycrystalline microstructure are well adapted to study crack initiation, transgranular fracture or cleavage often leading to the material failure. Thus, numerous crystal plasticity models have been developed to allow for accurate descriptions of intragranular plastic strains [2]. However the identification of their constitutive parameters remains challenging [3]. Full-field measurements can be performed at the microstructure scale by using a Scanning Electron Microscope (SEM) [4]. It provides spatially dense experimental information that is well suited for the validation of microstructural calculations and the identification of constitutive law parameters [5, 6]. In this paper, an inverse method for the identification of crystal plasticity parameters is presented, which is based on both the local displacement fields and the material homogenized behavior.

\section{KINEMATIC MEASUREMENTS USING DIGITAL IMAGE CORRELATION}

Kinematic measurements are performed by Digital Image Correlation (DIC) on the surface of a polycrystal of 316LN austenitic steel. For that purpose, a sequence of SEM images has been acquired during in situ tensile tests, using an FEI Quanta FEG 600 SEM. DIC requires a gray level texture with a dynamic range as large as possible with local contrast variations. In the present case, because the natural texture of the material does not provide enough contrast, a computergenerated random pattern is deposited onto the surface by microlithography [7]. The displacement fields are measured between two consecutive images with a continuous finite element based DIC procedure [8,9]. Thanks to a prior Electron 
Back-Scattered Diffraction (EBSD) acquisition providing grain boundaries and orientations, the displacement discretization is performed using an unstructured mesh taking as support the microstructure interfaces and overlaid on the first image of the sequence [10] as shown in Figure 1. It is composed of 3-noded triangular elements whose characteristic length is about 20 pixels (or $3 \mu \mathrm{m}$ ). The Region Of Interest (ROI) covers a $200 \mu \mathrm{m}$ side square surface that corresponds to 1500 pixels.

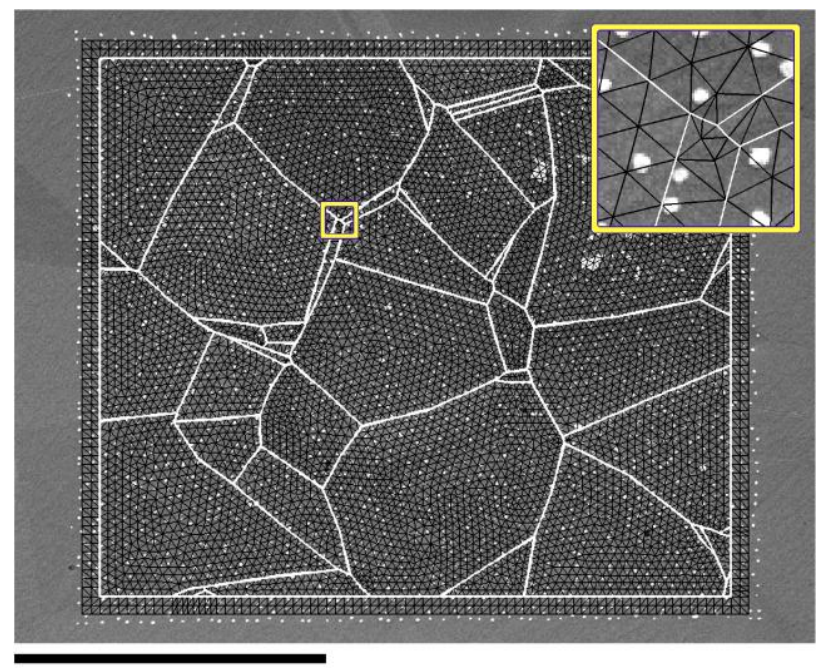

Fig. 1: Unstructured finite element mesh compatible with the underlying microstructure (shown as white lines) for DIC measurements. The scale bar is $100 \mu \mathrm{m}$

The noise of SEM imaging is relatively high, namely about $2 \%$ of the dynamic range of the image. In addition, the mesh is fine, so that plastic strain localizations may be captured in details. For those reasons, DIC calculations are assisted with mechanics [9] with a regularization length four times greater than the characteristic length of the mesh. The adopted DIC technique leads to a displacement uncertainty, as a Root Mean Square (RMS) value, of 0.029 pixel (or $4.3 \mathrm{~nm}$ ). Figure 2(a) shows the displacement field along the loading direction (horizontal) measured when the macroscopic strain is about $5 \%$. The corresponding strain field is shown in Figure 2(b). Strain localizations are successfully captured at some microstructure boundaries and inside some grains, whose local level reaches about $12 \%$, which is more than twice the macroscopic applied strain. The gray level residuals at this step of the loading are shown in Figure 2(c), proving the quality of the DIC measurement. In this figure, one may observe areas with higher values of the residual field that correspond to a change of the gray level in some grains over time that is likely to be induced by electron channeling contrast [11].

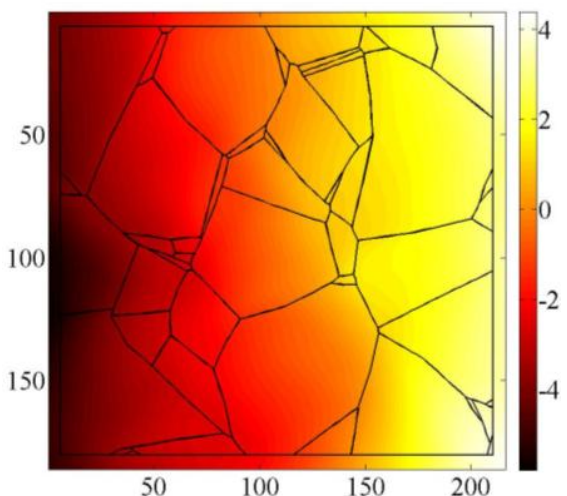

(a)

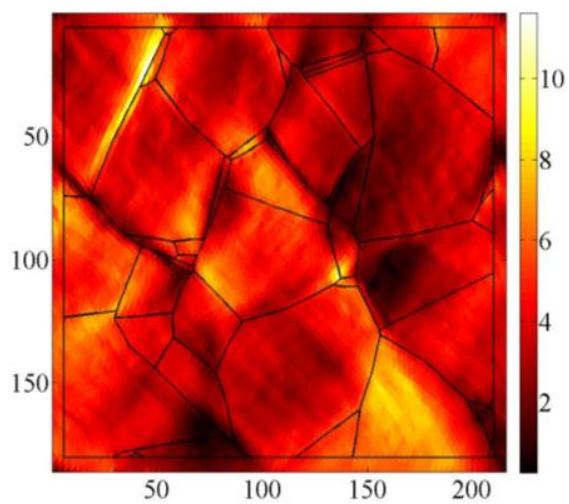

(b)

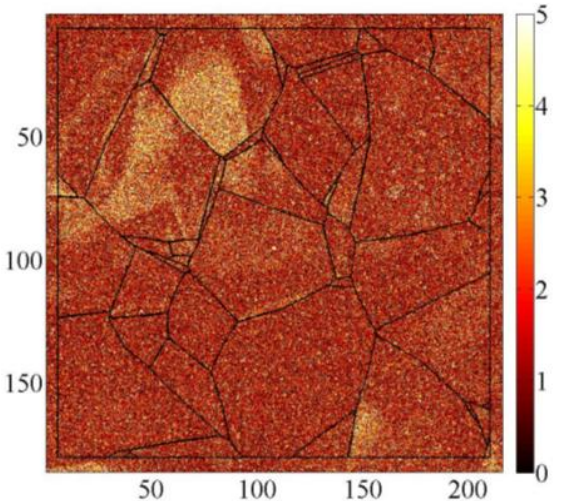

(c)

Fig. 2: Displacement field expressed in micrometers (a) and strain field in percents (b) along the horizontal loading direction measured by DIC for a macroscopic strain of $5 \%$. Corresponding correlation residuals expressed in percentage of the picture dynamic range (c). The axes are in micrometers. The microstructure boundaries are shown as black lines 


\section{SIMULATION USING A CRYSTAL PLASTICITY MODEL}

The simulation of the experimental tensile test is performed using the finite element software Code_Aster. The phenomenological crystal plasticity law proposed by Méric and Cailletaud [12] has been chosen in this study. It implies plastic flows $(1,2)$, isotropic (3) and kinematic (4) hardening relationships expressed for each of the 12 octahedral slip systems $s$

$$
\begin{gathered}
\dot{\gamma}_{s}=\dot{p}_{s} \frac{\tau_{s}-c \alpha_{s}}{\left|\tau_{s}-c \alpha_{s}\right|} \\
\dot{p}_{s}=\left\langle\frac{\left|\tau_{s}-c \alpha_{s}\right|-r_{s}\left(p_{s}\right)}{k}\right\rangle_{+}^{n} \\
r_{s}=r_{0}+q\left(\sum_{r=1}^{12} h_{s r}\left(1-e^{-b p_{r}}\right)\right) \\
\dot{\alpha}_{s}=\dot{\gamma}_{s}-d \alpha_{s} \dot{p}_{s}
\end{gathered}
$$

where $c, k, n, r_{0}, q, b, d$ are constitutive parameters, and $h_{s r}$ the coefficients of the interaction matrix between slip systems. The brackets \langle\rangle$_{\rangle_{+}}$denote the positive part of their argument. The three parameters associated with isotropic hardening are identified by homogenization using the model of Berveiller and Zaoui [13] and the experimental macroscopic stress-strain curve. The other parameters are set to previously identified values [14].

EBSD acquisitions do not provide a characterization of the microstructure in the bulk in a non-destructive way. As a consequence, a 2D modeling of the experimental aggregate is chosen in this study. The finite element calculation uses the same 2D mesh as that employed for the DIC measurements. This direct link between DIC and simulations allows the experimentally measured boundary conditions with their time evolution to be prescribed without interpolation or extrapolation. In addition, the assumption of plane stress condition is made, so that the 3D strain and stress tensors expected by the crystal plasticity law can be built.

Figure 3 shows the gap between the displacement fields along the loading direction for a macroscopic strain of about $5 \%$, when measured by DIC and simulated using the initial set of parameters. This difference is rather low with an RMS value of $0.3 \mu \mathrm{m}$ when compared to the dynamic of the displacement field of $9.3 \mu \mathrm{m}$. However, when compared to the standard measurement uncertainty $(4.3 \mathrm{~nm})$, the modeling error appears significant. The gap between displacement fields is to be minimized at each time step in order to identify parameters of the crystal plasticity law.

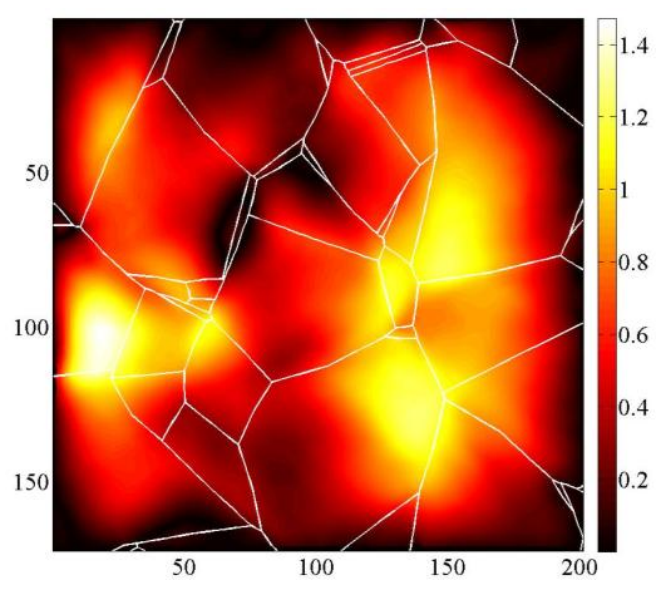

Fig. 3: Absolute value of the difference between measured and simulated displacement fields along the horizontal direction for a macroscopic strain of $5 \%$. The field and the axes are expressed in micrometers. The microstructure boundaries are shown as white lines 


\section{PARAMETER IDENTIFICATION}

A weighted Finite Element Model Updating (FEMU) procedure is proposed in this study in order to identify some parameters of the crystal plasticity law. It is based on the minimization of the combination of two least squares criteria. One is dealing with the displacement fields at the microstructural scale, denoted by $\chi_{u}$, the other one with the load level at the macroscopic scale, denoted $\chi_{F}$, such as the total cost function $\chi_{T}$ reads

$$
\chi_{T}^{2}(\mathbf{p})=(1-w) \chi_{u}^{2}+w \chi_{F}^{2}
$$

where $w$ is a weight to be chosen between 0 and 1 [15], and

$$
\chi_{T}^{2}(\mathbf{p})=(1-w) \frac{1}{2 \eta_{f}^{2} N_{d o f} N_{t}} \sum_{t}\left\{\Delta \mathbf{u}_{\mathbf{t}}\right\}^{T}[\mathbf{M}]\left\{\Delta \mathbf{u}_{\mathbf{t}}\right\}+w \frac{1}{\eta_{F}^{2} N_{t}}\{\mathbf{\Delta} \mathbf{F}\}^{T}\{\mathbf{\Delta} \mathbf{F}\}
$$

where $\mathbf{p}$ is the set of parameters to identify, $\left\{\Delta \mathbf{u}_{\mathbf{t}}\right\}$ the column vector of the difference at each degree of freedom at the time step $t$ between measured and simulated displacements, $\{\boldsymbol{\Delta} \mathbf{F}\}$ the column vector of the difference at each time step between the experimental load and that obtained by homogenization with the current value of $\mathbf{p} . N_{\text {dof }}$ and $N_{t}$ are respectively the number of degrees of freedom of the mesh and the number of time steps. $[\mathbf{M}]$ is the DIC matrix introduced with the standard deviation of noise of SEM images $\eta_{f}$ in order to weight the least squares criterion since these quantities are related to the covariance matrix $[\mathbf{C}]$ of the measured kinematic degrees of freedom [16]

$$
[\mathbf{C}]=2 \eta_{f}^{2}[\mathbf{M}]^{-1}
$$

Similarly, the standard deviation of the load resolution $\eta_{F}$ is introduced to normalize $\chi_{F}$. The minimization of $\chi_{T}$ with respect to the parameters is performed iteratively via a Gauss-Newton algorithm.

It is now applied to the identification of the parameters associated with the isotropic hardening of Méric-Cailletaud's law, focusing on the case of the experimental microstructure presented before. Figure 4(a) shows the identified values of the parameters $r_{0}$ and $b$ according to the chosen value of the weight $w$. This range of values is bounded by the extrema obtained on the one hand by considering only the macroscopic load level (i.e., for $w=1$ ), on the other hand by considering only the macroscopic displacement fields (i.e., for $w=0$ ). One may notice that with an equal weight (i.e., $w=0.5$ ), the identification

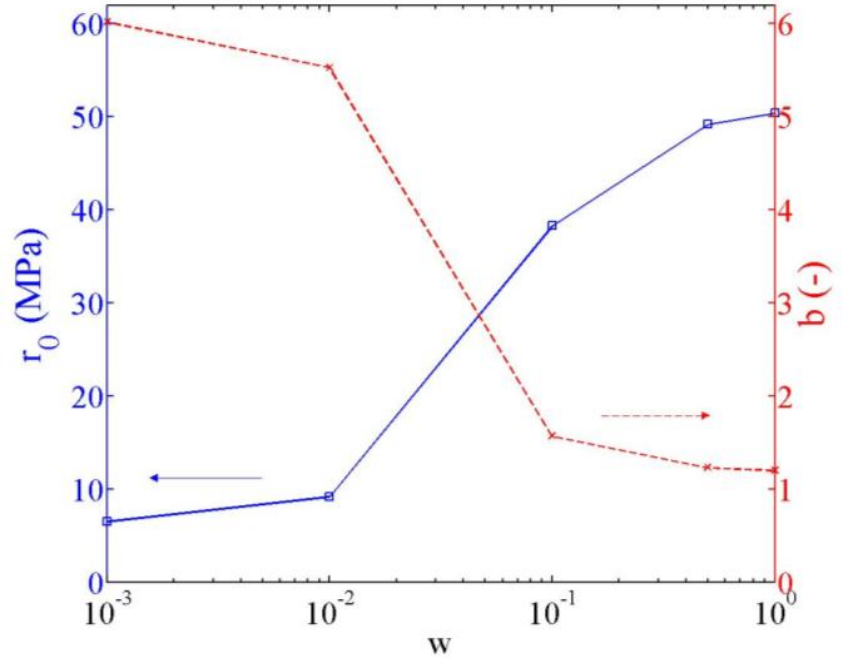

(a)

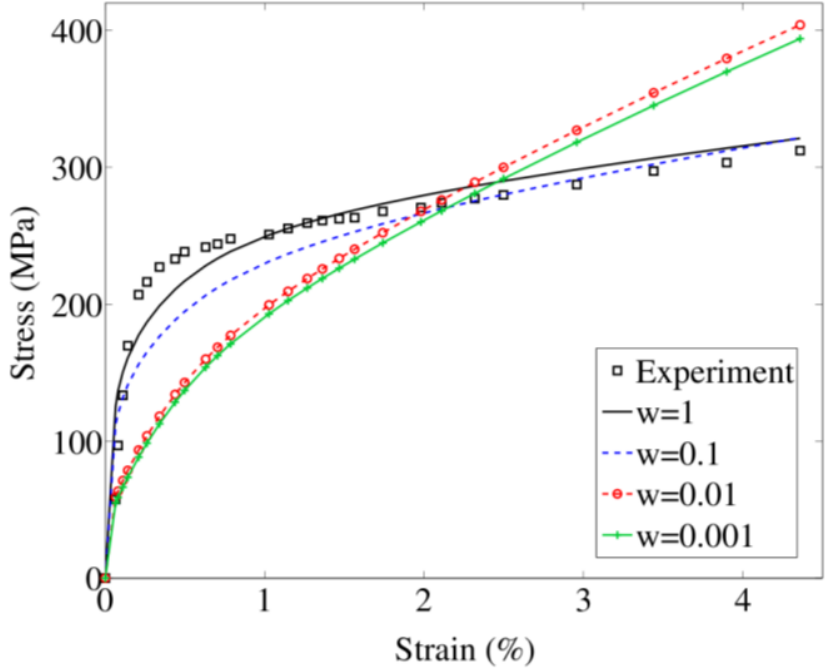

(b)

Fig. 4: Values of the identified parameters $r_{0}$ and $b$ as functions of $w$ (a). Stress-strain curves obtained by homogenization at convergence of the identification performed with different values of $w$, compared to the experimental curve (b) 
procedure is essentially driven by the minimization of $\chi_{F}$, which is equivalent to not considering displacement measurements. Therefore, a lower weight should be used in order to favor the decrease of the displacements gap more than the global equilibrium gap. However, it is observed in Figure 4(b) that decreasing $w$ increases the gap between the simulated homogenized behavior and experimental data. For this reason the cost function on the displacement fields needs to be combined with the one dealing with the load level in the identification procedure to keep a realistic prediction of the effective behavior. If the simulated stress-strain curves obtained with $w=0.01$ or $w=0.001$ do not appear realistic, the gap between the experimental curve and the simulated one with $w=0.1$ remains subjectively acceptable. In terms of displacement fields, the decrease of $\chi_{u}$ is moderate, from 21.80 when $w=1$ to 20.95 when $w=1$. It is worth noting that $\chi_{u}$ would reach unity if the model were perfect and only measurement uncertainty due to imaging noise were involved in the displacements gap.

An assessment of the effect of the mean grain size on the identification of the parameters is now presented. Four experimental microstructures are considered, which are obtained by different rolling and heat treatments from the same $316 \mathrm{LN}$ plate. The microstructures over the ROI in which the DIC measurements are performed during in situ tensile tests are shown in Figure 5. From left to right in this figure, the measured mean grain size is respectively $10 \mu \mathrm{m}, 50 \mu \mathrm{m}, 70 \mu \mathrm{m}$ and millimetric.
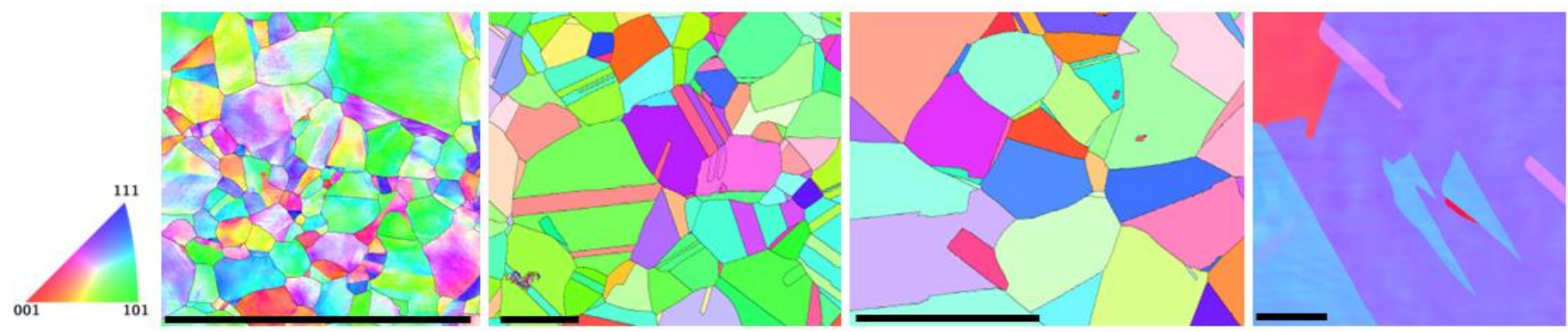

Fig. 5: EBSD inverse pole figures and grain boundary map of different microstructures over four ROI considered in this study. The scale bar is $100 \mu \mathrm{m}$

From the identified values of $r_{0}$ when the identification procedure is performed as previously but for each microstructure, one may identify the Hall-Petch relationship at the slip system scale. Usually, this equation is derived at the macroscopic scale from the yield stress dependence on the mean grain size. Herein, a similar dependence is sought between the critical resolved shear stress $r_{0}$ and the mean grain size $d$ such that

$$
r_{0}=c_{1}+\frac{c_{2}}{\sqrt{d}}
$$

where $c_{1}$ and $c_{2}$ are two constants. The result of the least squares fit is shown in Figure 6 when $w=1$ and $w=0.1$. We can see that the choice $w=0.1$ leads to a better fit of Hall-Petch's law with a correlation coefficient of 0.99 against 0.91 when $w=1$. This improvement tends to validate the choice of $w=0.1$ to optimize the simulated displacement fields.

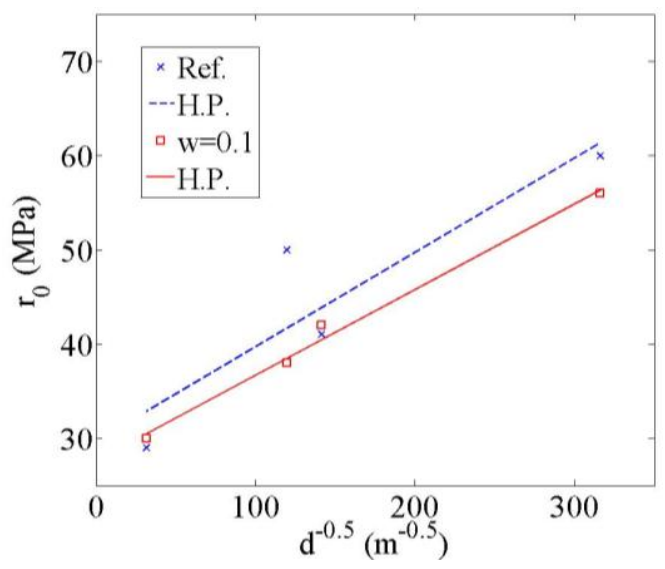

Fig. 6: Identification of the Hall-Petch (H.P.) law from the initial values of $r_{0}$ identified by homogenization $(w=1)$ and from those identified with $w=0.1$ 


\section{CONCLUSIONS}

It was proposed in this study to bridge kinematic measurements in austenitic stainless steel polycrystals and crystal plasticity calculations. On the one hand, displacement fields have been measured on the surface of an in situ tested specimen via digital image correlation based on a finite-element mesh that is itself tailored to the specimen microstructure as observed via EBSD. On the other hand, finite element simulations of the same experiment have been performed using the same mesh and the crystal plasticity law proposed by Méric and Cailletaud. The comparison between measured and simulated fields has led to the inverse identification of parameters of the law. It consists of a weighted finite element model updating technique using both displacement fields and load levels. It has been applied to the identification of the parameters associated with isotropic hardening. It has been shown that the identified values depend of the relative weight given to the displacement fields or the load levels. A weighting has been selected and has led to a very good fit of a Hall-Petch trend at the slip system scale when four different microstructures are considered. Identification residuals remain high, which is an indication that the assumed model is not fully consistent with the experimental observation. As a consequence, other crystal plasticity laws may be tested. Moreover, experimental approaches for characterizing the true 3D microstructure, which was one key information missing in the present study, may be considered in the future.

\section{REFERENCES}

[1] Leclercq S., Lidbury D., Van Dyck S., Moinereau D., Alamo A., and Al Mazouzi A., PERFORM 60 - Prediction of the effects of radiation for reactor pressure vessel and in-core materials using multi-scale modelling - 60 years foreseen plant lifetime. Journal of Nuclear Materials, 406(1), 193-203, 2010.

[2] Roters F., Eisenlohr P., Hantcherli L., Tjahjanto D.D., Bieler T.R., and Raabe D., Overview of constitutive laws, kinematics, homogenization and multiscale methods in crystal plasticity finite-element modeling: Theroy, experiments, applications. Acta Materialia, 58, 1152-1211, 2010.

[3] Hoc T., Crépin J., Gélébart L., and Zaoui A., A procedure for identifying the plastic behavior of single crystals from the local response of polycrystals. Acta Materialia, 51(18), 5477-5488, 2003.

[4] Sutton M.A., Li N., Joy D.C., Reynolds A.P., and Li X., Scanning electron microscopy for quantitative small and large deformation measurements Part I: Sem imaging at magnifications from 200 to 10.000. Experimental Mechanics, 47(6), 775-787, 2007.

[5] Héripré E., Dexet M., Crépin J., Gélébart L., Roos A., Bornert M., and Caldemaison D., Coupling between experimental measurements and polycrystal finite element calculations for micromechanical study of metallic materials. International Journal of Plasticity, 23(9), 1512-1539, 2007.

[6] Lim H., Carroll J.D., Battaile C.C., Boyce B.L., and Weinberger C.R., Quantitative comparison between experimental measurements and CP-FEM predictions of plastic deformation in a tantalum oligocrystal. International Journal of Mechanical Sciences, 92, 98-108, 2015.

[7] Guery A., Latourte F., Hild F., and Roux S., Characterization of SEM speckle pattern marking and imaging distortion by digital image correlation. Measurement Science and Technology, 25, 015401, 2014.

[8] Leclerc H., Périé J.-N., Roux S., and Hild F., Integrated digital image correlation for the identification of mechanical properties. MIRAGE 2009, LNCS, 5496, 161-171, 2009.

[9] Tomičević Z., Hild F., and Roux S., Mechanics-aided digital image correlation. Journal of Strain Analysis for Engineering Design, 48, 330-343, 2013.

[10] Guery A., Hild F., Latourte F., and Roux S., Slip activities in FCC polycrystals determined by coupling DIC and crystal plasticity calculations. Submitted for publication, 2014.

[11] Zaefferer S., and Elhami N.-N., Theory and application of electron channelling contrast imaging under controlled diffraction conditions. Acta Materialia, 75, 20-50, 2014.

[12] Méric L., Poubanne P., and Cailletaud G., Single crystal modeling for structural calculations: Part 1 - Model Presentation. Journal of Engineering Materials and Technology, 113, 162-170, 1991.

[13] Berveiller M., and Zaoui A., An extension of the self-consistent scheme to plastically-flowing polycrystals. Journal of The Mechanics and Physics of Solids, 26, 325-344, 1979.

[14] Guilhem Y., Basseville S., Curtit F., Stéphan J.-M., and Cailletaud G., Investigation of the effect of gran clusters on fatigue crack initiation in polycrystals. International Journal of Fatigue, 32, 1748-1763, 2010.

[15] Mathieu F., Leclerc H., Hild F., and Roux S., Estimation of elastoplastic parameters via weighted FEMU and integrated-DIC. Experimental Mechanics, in press, 2014, DOI: 10.1007/s11340-014-9888-9.

[16] Besnard G., Hild F., and Roux S., "Finite-Element" displacement fields analysis from digital images: Application to portevin-le chatelier bands. Experimental Mechanics, 46(6), 789-803, 2006. 